\title{
An Investigation of a New GSM Systems Jamming Technique without Existing Connections Disruption
}

\author{
Mladen Đ. Mileusnić, Predrag M. Petrović, Branislav R. Pavić, Verica B. Marinković-Nedelicki, \\ Vladimir S. Matić, and Aleksandar V. Lebl
}

\begin{abstract}
This paper presents a new method for jamming of GSM communications. The aim is to decrease voice connection quality, thus disabling users to understand each other, while keeping established connections. The jamming method parameters depend on the algorithm characteristics implemented in SACCH frame. It is proved for three mobile telephony codecs that it is possible to reach unsatisfactory voice connection quality $M O S<2$ due to jamming of a GSM communications channel. Errors in data transmission during the periods without jamming also cause voice connection quality impairment and this influence is analyzed. The method performances are compared to other solutions.
\end{abstract}

Keywords - E-model, GSM system jamming, jamming rate, SACCH frame.

\section{INTRODUCTION}

$\mathrm{H}$ OSTILE activities include various types of communications and each type of these communications has its specificity. There is the difference between the jamming of remote controlled improvised explosive devices (RCIED) activation messages and mobile telephone systems jamming (GSM or CDMA). It is also possible that the message for RCIED activation is transmitted by a mobile telephony system [1].

Paper received May 17, 2019; revised December 9, 2019; accepted December 10, 2019. Date of publication December 30, 2019. The associate editor coordinating the review of this manuscript and approving it for publication was Prof. Aleksandar Nešković.

This paper is revised and expanded version of the paper presented at the 26th Telecommunications Forum TELFOR 2018 [30].

The presented development is realized in the framework of the project TR32051, which is cofinanced by the Ministry of Education, Science and Technological Development of the Republic of Serbia 2011-2019.

Mladen Đ. Mileusnić is with IRITEL a.d., Batajnički put 23, 11080 Belgrade, Serbia (phone: 381-11-3073531, e-mail: mladenmi@iritel.com).

Predrag M. Petrović is with IRITEL a.d., Batajnički put 23, 11080 Belgrade, Serbia (phone: 381-11-3073488, e-mail: presa@iritel.com).

Branislav R. Pavić is with IRITEL a.d., Batajnički put 23, 11080 Belgrade, Serbia (phone: 381-11-3073487, e-mail: bane@iritel.com).

Verica B. Marinković-Nedelicki is with IRITEL a.d., Batajnički put 23, 11080 Belgrade, Serbia (phone: 381-11-3073486, e-mail: verica@iritel.com).

Vladimir S. Matić is with IRITEL a.d., Batajnički put 23, 11080 Belgrade, Serbia (phone: 381-11-3073485, e-mail: vmatic@iritel.com).

Corresponding author Aleksandar V. Lebl is with IRITEL a.d. Batajnički put 23, 11080 Belgrade, Serbia (phone: 381-11-3073403, e-mail: lebl@iritel.com).
IRITEL centre for radio communications has great, long standing experience and knowledge in the development of radio surveillance and jamming systems and equipment [29]. Three generations of GSM mobile phone or cellular jammers have been developed for various outdoor and indoor applications [9]. Figure 1 presents one of IRITEL cellular jammers solutions.

There are various approaches to the implementation of GSM communications jammers like those in references [10-13]. The simplest solutions are the active jammers [1012], which are always in the operation mode. This type of equipment is called Denial of service in [10] or constant jammers in [13]. The jamming device sends a noise signal only in the frequency range used for GSM signal transmission, thus decreasing a signal to noise ratio [10] or it applies continuous sweep signal jamming [11-12]. There are two possible reactions of GSM system in such a case: 1) it may continue to transmit the signal, which will not be received and 2) the channel will be considered as a busy one and not used for signal transmission [13].

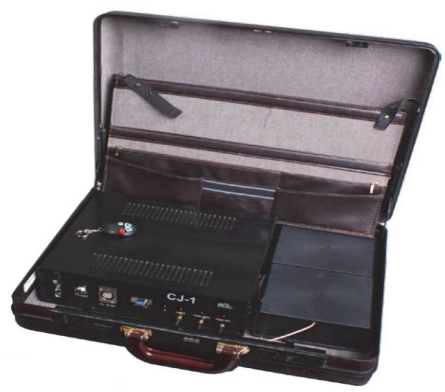

Fig. 1. CJ-1P - IRITEL cellular jammer.

Random jamming may be defined by the alternative periods of active and inactive jamming [13]. As a random jammer has no information about some channel whether it is busy or not, it is possible to jam an inactive channel and to miss a busy one.

There is a possibility that jamming is realized in a more intelligent way, than to continuously send the jamming signal. It means that a jamming device is dominantly in the receive mode with the goal to detect the intention of the mobile station (MS) to communicate with the base station (BTS). The jamming signal is generated only when such a communication exists. In this way the emission power is saved and electromagnetic pollution is decreased [14]. Such a jamming technique is called reactive jamming [13].

Another type of jammers is deceptive jammers [13]. In 
this case a jamming device continuously imitates usual GSM traffic using adequately defined frame structure transmissions, causing a GSM system to treat the considered channel as busy.

The spoofing technique (or „Intelligent Beacon Disablers" technique) is also applied to GSM signal jamming [10], [14]. In this technique the jammer forces the mobile phone to turn off itself. The jamming device behaves as a „beacon“, which orders the MS to disable its ringer or function. Similarly to this technique, „Intelligent Cellular Disablers device" is capable of detecting the presence of MS and of communicatibg with the BTS [14]. It sends information to the BTS that the user is in the ,quiet“" room, thus telling the BTS not to establish the call.

Intelligent jamming may be used in such a way that a jamming signal is sent only during some periods of GSM frame. These time periods are important for connection setup or for frame error detection or correction [13]. Such a jamming type is based on the precise synchronization with a GSM frame and on the knowledge of GSM frame structure.

There are several differences between GSM communications jamming and RCIED activation message jamming. GSM frame structure, applied signal power and the used bands and frequencies are known in advance. On the contrary, the characteristics of RCIED activation message (frequency range, emission power, modulation type, data rate, message length) are not known a priori. In the case of GSM systems, it is necessary to realize jamming continuously during a longer period of time. For RCIED activation message jamming it is typically required to prevent message appearance including its eventual later repetition. That's why GSM communications jamming is usually realized in an easier way, but applied jamming techniques could be similar in both cases.

The method presented in this paper is not complicated for realization and it is the nearest one to constant and random jamming. Constant jammers have the highest, constantly transmitted emission power, such that they are exposed to easier detection of their presence. Random jammers have a lower emission power, but, as already stated, jamming is not quite reliable because of jamming randomness. All variants of intelligent jamming are complicated for realization, although emission power is significantly lower. The primary goal in the majority of jamming methods is to force the termination of the established connection. On the contrary, a novelty of the method presented in this paper is that it tries to keep the established connections, while decreasing voice connection quality.

Section II presents the main elements of the GSM signal frame structure. Section III is a brief overview of E-model as the voice connection quality estimation method used in this paper. Section IV describes the new jamming method. Section $\mathrm{V}$ gives the calculated expected jamming results. Influence of errors when a signal is transmitted without the jamming action is analyzed in Section VI. The simulation program is briefly presented in Section VII. Concluding comments are included in Section VIII.

\section{A BRIEF OVERVIEW OF GSM FrAME STRUCTURE}

The units of GSM frame structure are a hyperframe, superframe, multiframe and frame specified in a descending length order [15 -17].

The structure of multiframe is very important in the analysis when a voice signal is transmitted (Fig. 2). The duration of this multiframe is $120 \mathrm{~ms}$. In this case, 24 of a total of 26 frames in the multiframe are intended for voice signal transmission $(\mathrm{TCH})$. The $25^{\text {th }}$ channel is called Slow Associated Control Channel (SACCH) and it is used to define the level and the timing advance when concrete connection parameters are defined. The $26^{\text {th }}$ channel is usually idle, as in Fig. 2, but it may be used as a SACCH channel when half rate connections are defined and used in TDMA frame structure.

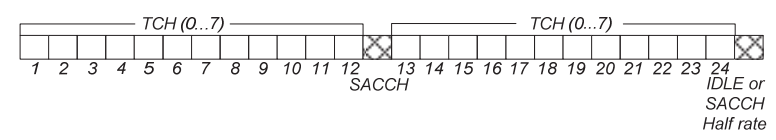

Fig. 2. The structure of multiframe when voice signal is transmitted.

Duration of each frame is $4.615 \mathrm{~ms}$ irrespective of the transmitted signal type. A frame is composed of 8 timeslots (TCH0...TCH7), which are forming the time multiplex signal (TDMA - Time Division Multiple Access). Here one timeslot represents a physical channel. The duration of one timeslot is $4.615 \mathrm{~ms} / 8 \approx 0.577 \mathrm{~ms}$. In this way, 8 voice signals are sent using one frequency of GSM system.

One timeslot consists of a total of 156.25 bits. This means that the duration of one bit is $T_{b}=577 \mu \mathrm{s} / 156.25 \approx 3.69 \mu \mathrm{s}$. The same is the duration of each bit in SACCH frame.

The other signalling data, important for connection realization, are transmitted in a signalling multiframe. Timeslots in this multiframe for signalling information transmission are called logical channels and their structure is the same as in the case of SACCH channel.

A total of 125 frequencies are used for GSM signal transmission in one direction (from BTS toward MSs, or opposite). These frequencies are forming a frequency multiplex (FDMA - Frequency Division Multiple Access). The frequencies of the multiplex are at mutual distance of $200 \mathrm{kHz}$.

In SACCH frame there is implemented a fire code, which is capable of correcting any single burst error, whose duration is not greater than 12 bits [16]. But, the primary role of this code is to detect errors. It may detect any single burst error in the frame with the length smaller than 40 bits, or two burst errors in the frame with the total length less than 24 bits. In this second case the maximum length of the shorter burst is 11 bits [13]. The code is also capable of detecting longer burst errors. These errors are detected in the great majority of cases except under rare conditions when a code polynomial corresponding to the data in $\mathrm{SACCH}$ frame is the multiple of the generator polynomial used to create the fire code. According to [18] the probability of not detecting such an error is $2^{-40}$.

Errors in a SACCH frame are used as criteria to estimate error rate in the whole signal intended for the considered user. But, no actions are initiated upon detecting the first error multiframe based on the algorithm implemented in 
SACCH frame. There is the procedure when the value of the counter is incremented by 1 each time an error is detected in SACCH frame and the value of this counter is decreased by 2 when there is no error in SACCH frame [1718]. The maximum value of this RADIO_LINK_TIMEOUT counter [17] and also its starting value at the moment of the connection beginning are usually limited to the value 20-48 [19]. It means that the percent of error SACCH frames may reach $J R=66 \%$ (where jamming ratio $J R$ presents the part of time when a jamming signal is transmitted), but that no actions are initiated to force the connection termination. This algorithm behaviour is exploited in our analysis.

The implemented modulation technique in GSM systems is Gaussian Minimum Shift Keying (GMSK). Its important characteristic is that each symbol presents one bit. This fact has to be considered in our analysis.

\section{VoICE CONNECTION QUALITY ESTIMATION}

E-model is the computational model for the estimation of voice connection quality. It joins the influence of various factors into one unique quality measure - a rating factor $R$ [20]. The value of $R$ is connected with Mean Opinion Score (MOS), which is between 1 and 5. The values of MOS and $R$ are connected by a formula and corresponding Fig. B.2 from [20]. The value $\operatorname{MOS} \leq 2$ may be, in any case, considered as unsatisfactory, i.e. the value when voice is not understandable. The corresponding value of rating factor is $R \leq 39$.

The main purpose of E-model is to express voice connection quality in Internet (VoIP) connections. But, according to [21], MOS is used as the measure of voice quality in mobile telephone connections. Taking into account that MOS and $R$ are mutually dependent variables, we implemented E-model to estimate the quality of mobile telephony connection.

According to E-model, a connection rating factor is [20]:

$$
R=94-I_{e-e f f}
$$

where effective equipment impairment factor $I_{e-e f f}$ includes impairments caused by the implementation of low-bit codec and influence of random signal loss.

The value of $I_{e-e f f}$ is calculated from the equation [20]:

$$
I_{e-e f f}=I_{e}+\left(95-I_{e}\right) \cdot \frac{P_{p l}}{\frac{P_{p l}}{B u r s t R}+B_{p l}}
$$

where:

- $I_{e}$ - equipment impairment factor when there is no signal loss;

- $\quad P_{p l}$ - transmitted signal loss probability (in \%);

- $\quad$ BurstR - burst ratio: the quotient of the average lengths of the lost signal parts in real transmitted signal and when signal parts are randomly lost;

- $\quad B_{p l}$ - robustness factor, which is specific for each coder type.

The characteristic of GSM mobile systems is burst loss of transmitted signal. But, when bits of coded signal are forming a voice channel, their order is changed, which means that burst loss of coded signal bits is replaced by random loss. That's why we use the value Burst $R=1$ in equation (2). We are focused on the codecs which are implemented in GSM systems. These are Full Rate (FR) codec (or GSM 06.10), Half Rate (HR) codec (or GSM 06.20) and Enhanced Full Rate (EFR) codec (or GSM 06.60). The values of $I_{e}$ and $B_{p l}$ for FR are 26 and 43, respectively [22], 23 and 15 for HR [23], [24] and 5 and 10 for EFR [23].

\section{THE Method OF JAMMING}

The applied jamming strategy may be explained on the base of Fig. 3. A jamming signal is transmitted during the periods, designated by $T_{\text {jam }}$ (Fig. 3a) and not transmitted during $T_{q}$. The jamming rate is, then:

$$
J R=\frac{T_{j a m}}{T_{j a m}+T_{q}} .
$$

Besides the value of $J R$, which must be $J R \leq 0.66$, it is important that $T_{\text {jam }}$ is not too long in order that the counter RADIO_LINK TIMEOUT does not reach the value smaller than 0 . We have chosen the value $T_{j a m} \leq 2 \cdot T_{f r} \approx 9.2 \mathrm{~ms}$. In this way it is possible that the value of counter is decreased only for two units consecutively as the result of jamming.

Jamming is realized as a frequency sweep (Fig. 3b). It means that signal frequency is linearly changed during $T_{j a m}$ from its minimum value $\left(f_{\min }\right)$, corresponded to the lower limit of GSM band to its maximum value $\left(f_{\max }\right)$. The signal frequency at the moment of starting the next $T_{\text {jam }}$ period is equal to the frequency at the moment of the previous $T_{j a m}$ period end.

The upper and lower bound frequency of one TDMA signal are designated as $f_{c u}$ and $f_{c d}$ respectively (Fig. $3 \mathrm{~b}$ ). It is $f_{c u}-f_{c d}=200 \mathrm{kHz}$. During the time while a jamming signal is changed between $f_{c d}$ and $f_{c u}$, it is possible that bits of GSM signal are incorrectly received (bits B03 and B04 and other hatched bits of GSM signal in Fig. 3c). Even in the case that jamming frequency is between $f_{c d}$ and $f_{c u}$ during the whole bit duration, it is possible that this bit is correctly received. The probability of false bit reception while a sweep signal frequency is in the range of considered TDMA signal frequency will be designated as $P_{\text {err }}$.

Let us designate the time of one sweep cycle as $T_{s w}$ and the duration of one bit (and, also, one symbol) in GSM signal as $T_{b}$ (Fig. 3c). The reciprocal values of these time intervals are sweep signal frequency $\left(f_{s w}\right)$ and the bit rate of GSM signal $\left(f_{b}\right)$. Then the jamming probability of the considered bit (i.e. that jamming frequency is in the range of the corresponding TDMA signal) is equal to

$$
P_{j}=\frac{T_{b}}{T_{s w}}=\frac{f_{s w}}{f_{b}} .
$$

The necessary condition is that $T_{b} \leq T_{s w}$. The optimum jamming strategy is to adjust $f_{s w}$ in such a way that it is $T_{b}=T_{s w}$. In this case the time interval while jamming frequency coincides with the GSM channel frequency is maximum and equal for each channel. If the jamming frequency is further increased, i.e. if it is $f_{b}<f_{s w}<2 \cdot f_{b}$, the time of frequencies coincidence is for some channels increased, but for others decreased compared to the optimum case. This time of coincidence depends on the fact whether the considered bit is jammed once or two times during its lifetime. 




Fig. 3. Implemented jamming strategy.

The necessary condition is that $T_{b} \leq T_{s w}$. The optimum jamming strategy is to adjust $f_{s w}$ in such a way that it is $T_{b}=T_{s w}$. In this case the time interval while jamming frequency coincides with the GSM channel frequency is maximum and equal for each channel. If the jamming frequency is further increased, i.e. if it is $f_{b}<f_{s w}<2 \cdot f_{b}$, the time of frequencies coincidence is for some channels increased, but for others decreased compared to the optimum case. This time of coincidence depends on the fact whether the considered bit is jammed once or two times during its lifetime.

Now the value $P_{p l}$ in (2) may be calculated as:

$$
P_{p l}=100 \cdot \mathrm{JR} \cdot P_{e r r} \cdot P_{j}=100 \cdot \mathrm{JR} \cdot \mathrm{BER} .
$$

\section{RESUlts}

The values of $R$, obtained on the base of equations (1)(5), are presented in Fig. 4 and Fig. 5. The results are presented for FR, HR and EFR codec as the function of $B E R=P_{e r r} \cdot P_{j}$. The parameter for these figures is $J R$.

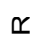

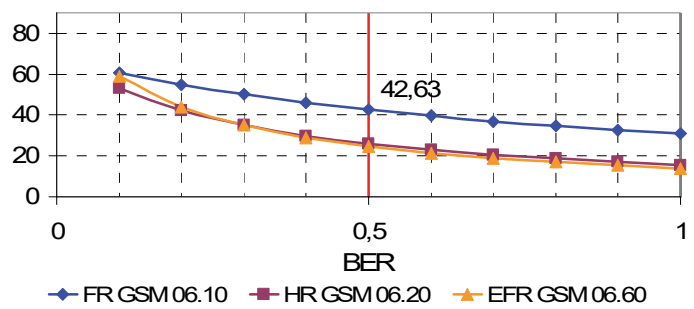

Fig. 4. Connection rating factor $R$ as a function of bit error rate $(B E R)$ for three GSM codecs when jamming rate is $J R=0.5$.

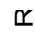

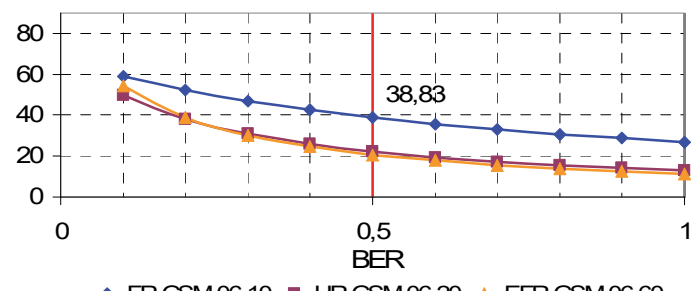

Fig. 5. Connection rating factor $R$ as a function of $B E R$ for three GSM codecs when jamming rate is $J R=0.63$.

For the practical analysis it is necessary that the value $P_{e r r}$ is known. In that case the values of $J R$ and $P_{j}$ are chosen according to Fig. 4 and Fig. 5 to achieve the value $R \leq 39$.
The voice connection will still exist, because the value of counter RADIO_LINK_TIMEOUT does not fall below 0 , but the voice connection quality is very bad $(\mathrm{MOS} \leq 2)$, where users do not understand each other.

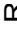



Fig. 6. Connection rating factor $R$ as a function of jamming rate $J R$ for three GSM codecs when BER is 0.5 .

Fig. 6 presents $R$ as the function of jamming rate $J R$ for FR, HR and EFR codec. The parameter for this figure is $B E R$. It is obvious from Fig. 6 that a signal coded by EFR or HR codec is easier for jamming (it is necessary to use a smaller $J R$ than when signal coded by FR is jammed to achieve the same $R$ ). The concrete values of JR to achieve a rating factor $R=39$ where voice quality is unsatisfactory are presented in Table I. The $J R$ and thus the total emission power may be more than two times lower when jamming HR and EFR coded signal than when FR coded signal is jammed. It is also obvious from Fig. 6 that connection quality of EFR codec becomes better than the quality of FR codec when $J R$ decreases. The results are presented for $J R \leq 0.04$. The value $J R=0$ would correspond to the situation when there is no jamming.

TABLE I - THE NECESSARY JR TO ACHIEVE $\mathrm{R}=39$ FOR VARIOUS GSM CODECS WHEN BER IS 0.5 .

\begin{tabular}{|c|c|c|}
\hline FR (GSM 06.10) & $\begin{array}{c}\text { HR (GSM } \\
06.20)\end{array}$ & $\begin{array}{c}\text { EFR (GSM } \\
06.60)\end{array}$ \\
\hline 0.623 & 0.24 & 0.25 \\
\hline
\end{tabular}

Example: FR codec is implemented in a GSM system. Let us suppose that $P_{e r r}=0.5$ is the probability of false bit reception when sweep signal jamming frequency is in the range of considered channel. Choose the value of $J R$ and $T_{s w}$ to achieve connection quality $\mathrm{MOS} \leq 2$.

Solution: it is $R>39$ (MOS $>2$ ) for $B E R=0.5$ if $J R=0.5$ when FR codec is applied (Fig. 4). That's why it is 
necessary to choose $J R=0.63$ (Fig. 5 ). As $R$ is now a bit less than $39(R \approx 38.8)$ for $B E R=0.5$, we must choose the maximum value $P_{j}=1$, i.e. $T_{s w}=T_{b}=3.69 \mu \mathrm{s}$, or $f_{s w}=271 \mathrm{kHz}$. There is a possibility that environmental conditions cause also a signal loss until it is $B E R \leq 0.66$ and to still have a connection, because it is RADIO_LINK_TIMEOUT $>0$.

Remark 1: the value $B E R=0.5$ is the typically achieved value when the jamming signal level is significantly greater than the level of the signal which has to be blocked. This is proved in [25] for MPSK modulated signals, where $M$ may be $2,4,8$ or 16 . The value $M=8$ is used for Enhanced Data GSM Evolution (EDGE) systems. When considering graphs from [26] for GMSK modulated signals, it may be concluded that the $B E R$ values are between 0.2 and 0.4 depending on the measurement (calculation) conditions for the signal to noise level ratio $S / N=0 \mathrm{~dB}$. The approximate $B E R$ formula for GMSK signals may be found in [27] and it shows that $B E R$ value tends to 0.5 when the ratio $S / N$ is increased. The detailed analysis of $B E R$ for GMSK modulated signals for $S / N<0 \mathrm{~dB}$ could be the subject of our future analysis.

Remark 2: under normal traffic conditions FR coding is applied to communications realization until some threshold of the number of instantaneously busy traffic channels [28]. HR codec is applied to connections only in the case of high traffic load when more than threshold number of channels is busy. That's why it is important to design jammer role also according to the requirements for HR codec.

\section{INFLUENCE OF SignAL TRANSMISSION ERRORS}

Until now we have supposed in this paper that jamming is realized under the conditions where there are no other error sources. This means that it has been $P_{p l}=0$ in the time intervals between two jamming signal bursts.

Let us now consider the situation when there is an error in the GSM signal when there is no jamming. The probability of such an error $\left(P_{b}\right)$ is very small in the case of Internet connections (transmission over optical cables), but may be significantly greater for mobile communications. The value of $P_{p l}$ in (2) is now expressed by

$$
P_{p l}=100 \cdot\left(J R \cdot B E R+(1-J R) \cdot P_{b}\right)
$$

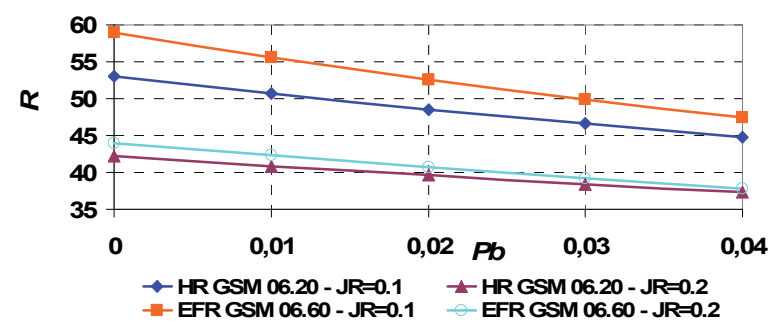

Fig. 7. Connection rating factor $R$ as a function of bit transmission error $P_{b}$ for two GSM codecs when $B E R$ is 0.5 and when $P_{b}$ is not negligible.

Fig. 7 presents a connection rating factor $R$ as a function of bit transmission error $\left(P_{b}\right)$ for two values of jamming rate: $J R=0.1$ and $J R=0.2$. During periods with a jamming signal GSM signal error probability is $B E R=0.5$ and when there is no jamming signal, GSM signal error probability is $P_{b}$. The results are presented for the values of $P_{b}$ between
$0 \%$ and $4 \%$. It is interesting to notice that the value of $R$ may fall to 39 or even less both for EFR and HR codec when $J R$ is 0.2 and $P_{b}$ is $3 \%$. When the value $J R$ is increased (in Fig. 7 when it is increased from 0.1 to 0.2 ), the influence of $P_{b}$ on the degradation of connection quality is decreased.

\section{METHOD VERIFICATION}

The presented jamming method is verified implementing our original simulation program, which is based on a set of random numbers generation. Each result is obtained after at least 100.000 times of executing a program simulation loop. The main purpose of the program has been to analyse the performances of combined sweep and barrage jamming $(S / N<0 \mathrm{~dB})$, but for an implementation in this program noise level is decreased $(S / N>0)$. Two main aims in the simulation have been: 1) to prove the $P_{p l}$ value obtained by (5) and 2) to estimate the maximum expected value of the register RADIO_LINK_TIMEOUT, thus confirming that a connection would not be disrupted during jamming. The corresponding signal in the simulation is obtained as the vector sum of RCIED activation signal, jamming sinusoidal signal and Gaussian white noise signal for the period $T_{j a m}$, while the signal consists of RCIED activation signal and noise signal during $T_{q}$ [8]. The jamming signal phase as also noise signal phase in relation to the RCIED activation signal directly follow from the uniformly distributed random number. Amplitudes of noise signals are calculated starting from the uniformly distributed random numbers, which are modified using the Box-Müller method [29]. The simulation is performed for the variable values according to the example from Section $\mathrm{V}$, including $J R=0.63$. According to simulation, $P_{p l}=0.312$, which satisfactorily agrees with the value $P_{p l}=0.315$ on the base of (5). The maximum values of the register RADIO_LINK_TIMEOUT as a function of the ratio $S / N$ during simulation are presented in Table II.

TABLE II - THE MAXIMUM VALUES OF RADIO_LINK_ TIMEOUT AS A FUNCTION OF $S / N$

\begin{tabular}{|c|c|}
\hline$S / N(\mathrm{~dB})$ & RADIO_LINK_TIMEOUT \\
\hline 10 & $<4$ \\
\hline 8 & 5 \\
\hline 7 & 8 \\
\hline 6 & $>20$ \\
\hline
\end{tabular}

VIII. CONCLUSIONS

A new method for jamming of GSM systems is presented in this paper. Compared to most other solutions, the aim is not to force the termination of the jammed communication, but to decrease the connection quality to the level where users cannot understand each other. In this way the probability to think about the jammer presence is decreased in comparison to the solutions when connection is terminated. This method is based on the behaviour of $\mathrm{SACCH}$ frame, fire code and the implemented criteria in it. The analysis is performed for the three most widely used GSM codec types. With respect to constant jamming, necessary emission power as well as radiation level are decreased. Jamming emission power depends on the value of $J R$, meaning that it is less than $66 \%$ of the jamming power in the case of constant jamming. The proposed 
method is similar to random jamming (there are periods of jamming activity and inactivity), but more reliable, because there is no danger of avoiding jamming of an active channel. The jamming emission power is higher than in the case of intelligent jamming. However, the jamming method is simpler, because there is no need to synchronize jamming signal transmission with GSM signal frame or to detect MS and communicate with BTS like in various methods of intelligent jamming.

\section{REFERENCES}

[1] A. GuLyÁS, "The radio controlled improvised explosive device (RCIED) threat in Afghanistan", AARMS, Vol. 12, No. 1, September 2013., pp. 1-11.

[2] "IRITEL High Frequency (HF) radio surveillance and jamming system," in the book M. Streetly: "Jane's Radar And Electronic Warfare Systems", IHS Global Limited, 2011.

[3] "IRITEL Very/Ultra High Frequency (V/UHF) radio surveillance and jamming system," in the book M. Streetly: "Jane's Radar And Electronic Warfare Systems", IHS Global Limited, 2011.

[4] P. Petrović, N. Remenski, P. Jovanović, V. Tadić, B. Pavić, M. Mileusnić, B. Mišković, "WRJ 2004 wideband radio jammer against RCIEDs", tehničko rešenje - novi proizvod na projektu tehnološkog razvoja TR32051 pod nazivom "Razvoj i realizacija naredne generacije sistema, uređaja i softvera na bazi softverskog radija za radio i radarske mreže“, 2011., http://www.iritel.com/images/pdf/wrj2004-e.pdf

[5] M. Mileusnić, B. Pavić, V. Marinković-Nedelicki, P. Petrović, D. Mitić, A. Lebl, "Analysis of jamming successfulness against RCIED activation", $5^{\text {th }}$ International Conference IcETRAN 2018, Palić, June 11-14, 2018., Proceedings of Papers, pp. 1206-1211.

[6] M. Mileusnić, B. Pavić, V. Marinković-Nedelicki, P. Petrović, D. Mitić, A. Lebl, "Analysis of jamming successfulness against RCIED activation with the emphasis on sweep jamming", Facta Universitatis, Series Electronics and Energetics, Vol. 32, No. 2, June 2019., pp. 211-229.

[7] M. Mileusnić, P. Petrović, B. Pavić, V. Marinković-Nedelicki, J. Glišović, A. Lebl, I. Marjanović, "The radio jammer against remote controlled improvised explosive devices", $25^{\text {th }}$ Telecommunications Forum (TELFOR), November 21-22, 2017., Proceedings of Papers, pp. 151-154.

[8] M. Mileusnić, P. Petrović, B. Pavić, V. Marinković-Nedelicki, V. Matić, A. Lebl, "Jamming of MPSK modulated messages for RCIED activation", $8^{\text {th }}$ International Scientific Conference on Defensive Technologies OTEH 2018, Belgrade, 11-12. October 2018, pp. 380385.

[9] N. Remenski, B. Pavić, P. Petrović, M. Mileusnić, V. MarinkovićNedelicki, "Integrisana radio-oprema za zaštitu prostora od mobilnih veza (Treća generacija radio-opreme), tehničko rešenje - novi proizvod s oznakom CJ-1P na projektu tehnološkog razvoja TR11030 "Razvoj i realizacija nove generacije softvera, hardvera $\mathrm{i}$ usluga na bazi softverskog radija za namenske aplikacije", 2010., http://www.iritel.com/images/pdf/cj-1p-e.pdf, (also published in the book M. Streetly, Jane's Radar And Electronic Warfare Systems. IHS Global Limited, 2011.)

[10] P. Naresh, P. Raveendra Babu, K. Satzaswathi, "Mobile phone signal jammer for GSM, CDMA with pre-scheduled time duration using ARM7", International Journal of Science, Engineering and Technology Research, Vol. 2, Issue 9, September 2013., pp. 17811784.

[11] Phantom Technologies LTD., TSecNet s.r.l., SGS, "Selective cellular jammer", 2017, http://www.tsecnet.com/assets/docs/ TSECNET\%20Cellular_Selective_Jammer.pdf
[12] GBPPR $800 \mathrm{MHz}$ cellular phone jammer, http://67.225.133.110/ gbpprorg/mil/celljam1/

[13] G. Timm, "An investigation into jamming GSM systems through exploiting weaknesses in the control channel forward error correction scheme", Dissertation for the degree of Masters of Science in Engineering, University of Witwatersrand, Johanesburg, 2017.

[14] A. Jisrawi, "GSM-900 mobile jammer", Jordan University of Science and Technology, 2006.

[15] ETSI TC-SMG, GSM Technical Specification GSM 05.02, "Digital cellular telecommunications system (Phase 2+); Multiplexing and multiple access on the radio path", May 1996.

[16] ETSI TC-SMG, GSM Technical Specification GSM 05.03, "Digital cellular telecommunications system (Phase 2+); Channel coding", version 5.2.0, August 1996.

[17] ETSI TC-SMG, GSM Technical Specification GSM 05.08, "Digital cellular telecommunications system (Phase 2+); Radio subsystem link control", version 5.0.0, May 1996.

[18] J. Ebersprächer, H-J. Vögel, C. Bettstetter, C. Hartmann, "GSM Architecture, Protocols and Services", 3rd Edition, ISBN 978-0-47003070-7, John Wiley and Sons, 2009.

[19] D. K. Arora, C. H. Snow, A. Abdel-Samad, N. Almalki, D. P. Hole, "Radio link timeout procedure for call re-establishment", EP2471334A1, European Patent Office.

[20] ITU-T, Recommendation G.107, "The E-model, a Computational Model for Use in Transmission Planning", Series G: transmission systems and media, digital systems and networks, June 2015.

[21] Agilent Technologies, "Optimizing your GSM network today and tomorrow, using drive testing to estimate downlink speech quality", Application Note 1325, July 2001.

[22] ITU-T, SG12 - D.106, "Estimates of Ie and Bpl parameters for a range of CODEC types", Telchemy Incorporated, January 2003.

[23] ITU-T, Recommendation G.113, "Transmission impairments due to speech processing", Series G: transmission systems and media, digital systems and networks, November 2007

[24] M. Pajić, "Android aplikacija za E model iz ITU-T G.107 preporuke", diplomski rad, Elektrotehnički fakultet Beograd, septembar 2014, in Serbian.

[25] V. Marinković-Nedelicki, A. Lebl, M. Mileusnić, P. Petrović, B. Pavić, "BER Calculation for Sweep Jamming of MPSK Modulated RCIED Activation Message Signals", 2019 18 $8^{\text {th }}$ International Symposium INFOTEH-JAHORINA (INFOTEH), Proceedings, Session for Communication systems and technologies (KST-1.5), Jahorina, 20-22. March 2019., ISBN: 978-1-5386-7073-6, pp. 1-6.

[26] S. S. Shin, "Differetially Detected MSK and GMSK Modulation schemes in CCI Channels for Mobile Cellular Telecommunication Systems", a thesis submitted for the degree of master of applied science, The Faculty of Graduate Studies, Department of Electrical Engineering, The University of British Columbia, October 1992.

[27] R. Anane, K. Raoof, R. Boullegue, "On the Evaluation of GMSK Scheme with ECC Techniques in Wireless Sensor Networks", International Journal of Wireless \& Mobile Networks (IJWMN), Vol. 7, No. 2, April 2015., pp. 17-28.

[28] D. Mitić, A. Lebl, M. Mileusnić, B. Trenkić, Ž. Markov, “Traffic Simulation of GSM Cells with Half-Rate Connection Realization Possibility“, Journal of Electrical Engineering, Vol. 67, No 2, April 2016., pp. 95-102.

[29] A. Lebl, M. Mileusnić, B. Pavić, V. Marinković-Nedelicki, P. Petrović, "Programmable Generator of Pseudo-White Noise for Jamming Applications", $27^{\text {th }}$ Telecommunications Forum (TELFOR), Belgrade, November 26-27, 2019., Proceedings of Papers.

[30] M. Mileusnić, P. Petrović, B. Pavić, V. Marinković-Nedelicki, V. Matić, A. Lebl, "A New Method of GSM Systems Jamming Based on Connection Quality Impairment", 26 th Telecommunications Forum (TELFOR), Belgrade, 20-21. November 2018., Proceedings of Papers, pp. 160-163. 